\title{
The biological basis of language: insight from developmental grammatical impairments
}

\section{Citation}

Van der Lely, Heather K.J., and Steven Pinker. 2014. The Biological Basis of Language: Insight from Developmental Grammatical Impairments. Trends in Cognitive Sciences 18(11): 586-595.

\section{Published Version}

doi:10.1016/j.tics.2014.07.001

\section{Permanent link}

http://nrs.harvard.edu/urn-3:HUL.InstRepos:23597720

\section{Terms of Use}

This article was downloaded from Harvard University's DASH repository, and is made available under the terms and conditions applicable to Open Access Policy Articles, as set forth at http:// nrs.harvard.edu/urn-3:HUL.InstRepos:dash.current.terms-of-use\#OAP

\section{Share Your Story}

The Harvard community has made this article openly available.

Please share how this access benefits you. Submit a story.

\section{Accessibility}


The Biological Basis of Language:

\title{
Insight from Developmental Grammatical Impairments
}

\author{
Heather K. J. van der Lely \\ Steven Pinker ${ }^{1}$ \\ Department of Psychology, Harvard University.
}

1. Corresponding author

Steven Pinker

Department of Psychology

Harvard University

William James Hall 970

33 Kirkland Street

Cambridge, MA 02138

USA

Key words:

Specific Language Impairment

Neurolinguistics

Genetics of Language

Brain and language

Language disorders 


\section{Abstract}

Specific Language Impairment (SLI), a genetic developmental disorder, offers insights into the neurobiological and computational organization of language. A subtype, GrammaticalSLI, involves greater impairments in "extended" grammatical representations, which are nonlocal, hierarchical, abstract, and composed, than in "basic" ones, which are local, linear, semantic, and holistic. This distinction is seen in syntax, morphology, and phonology, and may be tied to abnormalities in the left hemisphere and basal ganglia, consistent with new models of the neurobiology of language which distinguish dorsal and ventral processing streams. Delineating neurolinguistic phenotypes promises a better understanding of the effects of genes on the brain circuitry underlying normal and impaired language abilities. 


\section{Introduction}

With the lack of animal models for language, and the inability to use invasive procedures with humans except out of medical necessity, our knowledge of the neurobiology of language has long depended upon natural experiments. During the 19th and 20th centuries, studies of patients with acquired brain lesions provided key insights [1-3]. Understanding of language in the $21^{\text {st }}$ century promises to be enriched by data from developmental disorders. Specific Language Impairment (SLI), a family of language impairments in otherwise normal children, is highly heritable and has been linked so far to four genes. These discoveries provide a new route to understanding the complex pathways from genes and environment to the neural systems underpinning language.

This understanding depends, however, on breaking down the coarse categories of "language" and "language impairment" and examining the way that specific components of language are affected in specific disorders, and how they correlate with brain function and structure. That is, rather than searching for a direct link from genotype to behaviour, we suggest linking genetic variants with alterations in the neural substrates of subcomponents of language processing.

\section{Specific Language Impairment (SLI)}

SLI is a heterogeneous family of impairments which affect the acquisition of language in $7 \%$ of children, an average of two in every classroom [4]. It frequently co-occurs with other disorders such as Dyslexia, Autistic Spectrum Disorders, and Attention Deficit and Hyperactivity Disorder [5, 6], with which it also shares some phenotypic and genotypic characteristics [7, 8]. Many genetic variants contribute to SLI across individuals, consistent with the heterogeneity of the disorder [7]. Despite this heterogeneity, the majority of children are impaired in grammatical functions, particularly syntax and morphology, and often 
phonology as well (Box 1) $[4,9,10]$. One of us has identified a subtype of the broad SLI category called Grammatical SLI (G-SLI) which is concentrated in grammar, though it may embrace secondary deficits, for example, in the lexicon [4, 9-11], though see also [12, Rice, 1998 \#2042, 13]. Though discovered in English-speaking children, G-SLI has since been identified in other languages [14-16].

\section{Grammatical Phenotypes of SLI}

This paper focuses on what G-SLI can reveal about the structure and neural instantiation of language. Crucially, G-SLI is not a global impairment of language or even of grammar but is strongly manifested in certain aspects of linguistic performance while leaving others largely intact. This raises the possibility that the contrast reflects a key division within the neural or genetic substrates of language. In particular, children with G-SLI have difficulty interpreting and producing syntactic structures such as wh-questions, the passive voice, and tensemarking; words that must be grammatically inflected in real time; and complex phonological structures embracing multiple syllables and clusters of phonemes. But they have age-typical performance on syntactic tasks in which lexical semantic information is sufficient, on morphological tasks in which stored, nondecomposed forms are sufficient, and on phonological tasks in which strings of phonological units are sufficient. The problems with composed forms, moreover, persist into adulthood. We suggest that this pattern of deficits may reflect two modes of grammatical representation and processing we call Basic and Extended (Box 1), and that individuals with G-SLI are specifically impaired in processing Extended representations.

\section{Extended versus Basic Syntax}

Extended Syntax involves hierarchical structures and dependencies between words, often spanning the entire clause, which are computed in real time. For example, in wh-questions 
such as Who did Joe see _ ? the wh-word and the empty position after see are in a dependent relation, which may be analysed as the movement of the word from its original position in an underlying structure (Figure 1). Additionally, Extended syntax is abstract: the assembly and interpretation of phrases depend on their grammatical categories (noun, verb, tense) and relations (subject, head, complement) defined by correlated privileges of occurrence. Abstraction is central to grammar: the acquisition of abstract symbolic rules enables a person to generalize a pattern learned from a finite number of exemplars to an infinite number of new ones which need not resemble them in sound or meaning $[17,18]$.

Basic Syntax, in contrast, involves relations between words that can be determined from the meanings of the words themselves or from dependencies between adjacent words. Basic syntax may consist of holistic representations, in which sequences are stored and retrieved without necessarily analysing their grammatical structure, and instead are linked directly to their semantic and pragmatic properties and their ordering relative to adjacent units.

Extended and Basic representations differ in their processing requirements. In basic syntax, words and their features (number, gender, meaning) can be inserted directly from the lexicon, whereas in Extended syntax, relations between words within and across hierarchical units must be computed by operations such as movement and feature checking or unification. Figure 1 shows some of the extended syntactic relations which must be computed, according to a major theory of grammar [19], in assigning tense to a clause and in producing or interpreting wh-questions; other theories require operations of comparable complexity.

\section{Impairments in Syntax}

Table 1 shows the results of a variety of experiments, differing widely in their methods and processing demands, in which children with G-SLI display problems with Extended syntax 
(specifically, wh-questions similar to those illustrated in Figure 1), but perform well in control conditions requiring only basic syntax or lexical semantics $[9,10,20]$.

Experiments testing other syntactic constructions show similar patterns. For example, teenagers with SLI rely on number information as a shortcut to understanding relative clauses in the same way that unimpaired six-year-olds do [21]: upon hearing The cat that is chasing the dogs is black, they understand that the cat is black rather than the dog, because plural dogs cannot be the subject of singular is black, whereas with The cat that is chasing the dog is black, which provides no such cue, their performance is close to chance. Other examples of structures which require extended syntax for interpretation, and with which individuals with SLI show comprehension difficulties, are reversible passive sentences, such as The truck was hit by the car [22]. Likewise, they have trouble assigning an ambiguous pronoun to an antecedent specified by grammatical constraints, as in Mowgli said $\mathrm{Baloo}_{j}$ is tickling him (in which Baloo must be tickling Mowgli, not himself, as opposed to Mowgli ${ }_{i}$ said Baloo $_{j}$ is tickling himself, where Baloo can only be tickling himself), while having no trouble assigning pronouns to antecedents of the same gender, as in Jane says Paul is tickling her, where her can only be female Jane, not male Paul [23]. Similar patterns are found in SLI children speaking other languages [15]. When the memory load required to link a pronoun to its antecedent is controlled or reduced (as in agentless passive sentences such as The truck was hit), or when memory abilities are matched in a control group, the individuals with G-SLI still have more trouble with sentences requiring extended syntactic analysis $[9,21,24]$. G-SLI children's difficulties are also seen in their production, such as the omission of tense-marking (as in Yesterday I fall down $[9,25]$, a phenomenon at the intersection of syntax and morphology.

The abstractness of extended syntax also poses problems. When teenagers with G-SLI try to learn simple abstract rules, such as $A B B$ vs $A B A$ (realized in contrasts such as vi ko ko 
versus vi ka vi), they failed learn the instances, to generalize them to new sequences, and to show the expected electrophysiological brain response to violations.

\section{Extended versus Basic Morphology}

G-SLI also impairs morphology in a selective fashion which targets abstract combinatorial operations. Extended morphological objects are generated, perceived, and represented as combinations of two or more morphemes, whereas Basic ones are stored and retrieved as wholes, or at best as containing parts which do not freely combine with other parts $[9,10]$. For example, in English, irregular past-tense forms (ate, bought) are basic and handled by memory, while regular past-tense forms (jumped, agreed) are morphologically complex and may be computed from the verb stem and -ed suffix, particularly when the verb is rare or novel $[18,26]$,

\section{Impairments in Morphology}

Problems with regular inflectional morphology (an Extended process) are a hallmark of SLI in English speakers [9, 27-30]. In contrast to unimpaired children, children with G-SLI seem to habitually store regular forms as wholes: they have more trouble with low-frequency than with high-frequency regular forms (suggesting they have memorized the high-frequency ones); they are no better at producing regular than irregular forms; they produce regular plurals inside compounds (rats-eater), which unimpaired speakers deem ungrammatical; and they have great difficulty inflecting novel verbs and nouns, where the demand on computation is highest and memory lookup is unavailable $[9,10,28-30]$.

Similarly, even when decomposition of extended morphological forms would facilitate production and perception, children with G-SLI link the word's sound directly to its lexical form in memory $[9,10]$. For example, words ending in sequences that never occur in 
monomorphemic forms, such as $v d$ in loved and gd in hugged, or the German fst as in $d u$ kaufst (you buy), must have a morphological boundary falling within the word-final cluster, making them unambiguously inflected. Unimpaired individuals are sensitive to this cue; GSLI individuals are not $[9,10,31]$.

At first glance, derivational morphology (Box 1) ought to parallel inflectional morphology, with predictable, freely generated regular forms (e.g., uncorkability) and idiosyncratic, stored irregular ones (e.g., destroy-destruction). Nonetheless with unimpaired speakers even regular derived forms seem to be stored and retrieved as wholes [32], presumably because derivational suffixes have more semantic content than inflectional ones and their combinations are more likely to be lexically specific. We speculate that this may parallel the surprising ability of G-SLI individuals to provide regular derived forms on demand, such as sillier from silly and rocky from rock [33]. Though the children rarely omit derivational suffixes, they occasionally misapply them, as when they convert happy to happer or happest rather than happier and happiest, and frills to frillsy rather than frilly. This pattern may reflect their mosaic of abilities: they have slots in memory for familiar derived forms but are impaired at reconstructing the sequence of morphemes that fills it.

\section{Extended versus Basic Phonology}

We now heuristically apply the Extended-Basic distinction to a third component of language, phonology. In this extension, Basic phonological representations consist of strings of phonemic segments made up of distinctive features. Extended phonological representations are hierarchically organized into prosodic units of increasing size: the syllable, the foot, the prosodic word, the intonational phrase, and the utterance [34].

In speech perception, the Basic and Extended aspects of phonological representations are initially processed via independent streams which are then later integrated [35, 36]. Basic 
representations require the analysis of rapidly changing events in the speech signal within a narrow time window. This enables acoustic distinctions to be drawn between phonemes (such as the place contrast between $b$ and $d$ ) and phoneme sequences (such as ts versus st). Basic phonology is necessary for building segments into syllables.

In contrast, Extended representations require the analysis of more slowly unfolding events in the speech signal using a wider sampling window. Extended phonology is necessary for building syllables into feet, words, and larger prosodic domains. Amongst other things, it handles word stress, syllable rate, and intonation.

\section{Impairments in phonology}

Contrary to a common assumption that SLI originates in a difficulty in processing transient speech signals which then propagates to higher-level representations, individuals with G-SLI have few problems processing Basic phonological representations such as segments. They are age-appropriate in categorical perception of phonemes such as $b$ and $d[4,37]$, and children with broad SLI can distinguish minimal segmental contrasts between stored words, such as van and fan [37]. Children with broad SLI also compensate for coarticulation effects that can mask phonemic contrasts; for example, they recognize that brow $[n]$ roof and brow $[\mathrm{m}]$ bell contain instances of the word brown but that brow $[\mathrm{m}]$ lamp does not [38]. They can also follow instructions to exchange segments in words, such as converting sad cat to cad sat [37].

Basic phonology is also sufficient for people with broad SLI to perceive and articulate adjacent sounds in consonant clusters in real and novel words. Their problem consists in putting them in the wrong structural position, saying flakesta rather than faklesta, presumably because they fail to represent details of the extended phonological structure [39]. Similarly, they have more trouble producing regularly inflected forms that end in 
complex clusters (jumped) than those with simple endings (sewed) [40]. This may explain their reduction of trisyllabic derived forms such as happiest to *happest [Marshall, 2007, \#7929\}.

Individuals with G-SLI also have difficulties with the extended representations needed to handle prosody. In non-word repetition tasks, they make more errors in producing consonant clusters as the words become more prosodically complex [41]. Children with broad SLI also have difficulty using prosodic cues to distinguish phrases such as [red] [and black and pink socks] from [red and black] [and pink socks] [42].

\section{Neural Substrates of the Distinction between Basic and Extended}

\section{Grammar}

Recent advances using EEG, MEG, fMRI, and DTI tractography have led to sophisticated new models of the neural organization of language [35, 43-45]. They allow us to assess whether the Extended processes which pose the greatest problems in G-SLI implicate brain networks that are different from those supporting Basic processes.

\section{Syntax}

The new models (Figure 2) go beyond the classic Broca's and Wernicke's areas and distinguish at least three fronto-temporal networks related to syntactic processing [43]. First, a dorsal pathway links Brodmann Area 44 (a part of Broca's Area) via the arcuate fasciculus (AF) to the posterior Superior Temporal Gyrus (a part of Wernicke's Area). It is said to underlie "hierarchical structures independent of semantics" in natural and artificial languages, and "syntactically complex sentences," particularly those involving movement $[43,44]$. It is associated with the rapid (100-200 ms) Early Left Anterior Negativity [44] and 
Syntactic-Mismatch Negativity [46-48], which we will lump together as Early Syntactic Brain Responses (ESPRs).

There are also two ventral pathways. One, which supports "local phrase structure," links the frontal operculum (adjacent to Broca's) via the Uncinate Fasciculus (UF) to the anterior STG, and it is associated with a later (300-700 ms) Left Anterior Negativity (LAN). The other, supporting retrieval of stored words and lexical semantic processing, links BA45 (another part of Broca's Area) via the Extreme Capsule Fibre System (ECFS), to the posterior temporal lobe, particularly the Superior Temporal Gyrus and Superior Temporal Sulcus.

The functions of the dorsal and ventral syntactic circuits correspond well to what we call Extended and Basic syntax. Interestingly, the dorsal pathways, unlike the ventral ones, do not fully mature until around 7 years [49]. Accordingly, the brain responses of 2-year-olds are sensitive to sentences that violate Basic syntax, with a left lateralised ERP, but not to violations of Extended syntax [50], which only develops by 7-9 years [20]. Interestingly, the dorsal pathways in human brains differ substantially from those in other primates, suggesting that phylogenetic changes to the dorsal pathway may have been a key driver of the evolution of language [43].

A still later neural response, which is elicited with both extended and basic syntax, reaches a maximum at around 600 msecs (the P600), and is observed bilaterally in frontal or parietalcentral locations; it represents a second-pass reanalysis under participants' strategic control [51]. The P600 also involves subcortical structures, namely the caudate nucleus of the basal ganglia, which responds to ungrammatical and ambiguous sentences [52].

\section{Morphology}

Two aspects of morphology require Extended processing: the recognition that a word must be inflected in certain contexts (e.g., in tensed clauses; Figure 1), and the computation of the 
appropriate inflectional form, which for regular verbs (particularly novel and rare ones) involves the analysis of the word as a stem plus a suffix. Both computations are composed, hierarchical, and abstract (though local), and as mentioned, both present difficulties to children with G-SLI. Both components of morphological processing have long been associated with Broca's area [26, 53, 54, 55 4760]. A recent study using high-precision intracranial recordings revealed distinct areas within Broca's area corresponding to the selection of the appropriate tense or number (at $\sim 320 \mathrm{msec}$ ) and to the computation of the appropriate morphological form (at $450 \mathrm{msec}$ ) [56]. fMRI of the same patients implicated the posterior superior temporal cortex as well. These studies suggest that as with Extended syntax, Extended morphology is mediated by a dorsal pathway.

These studies did not distinguish regular from irregular inflection, but a comprehensive study of priming patterns in aphasic patients, together with fMRI in normal adults, specifically tied regular inflection to "a core decompositional network linking left inferior frontal cortex with superior and middle temporal cortex, connected via the arcuate fasciculus" [45]—namely, a dorsal pathway similar to the one identified for Extended syntax (Figure 3). A recent metaanalysis of neuroimaging studies similarly found that regular inflection consistently activates BA 44 [57]. As with syntax, studies regular inflection also appears to engage the head of the caudate nucleus [52-54].

In contrast, the computation of irregular forms involves storage and retrieval from lexical memory, a Basic process. Studies with aphasic patients and with fMRI suggest that its neural substrate is largely distinct from that for regulars, involving bilateral posterior temporoparietal regions $[45,53,54,58,59]$. They are thought to be part of a larger, complex network for lexical storage and retrieval. 
Yet another pattern was found with derivational morphology. As with inflection, some derived words are regular and transparent in their structure and could be analysed by rules (bravely), whereas others are opaque and irregular (archer, depth). However, regular derived forms do not seem to implicate the dorsal network, nor do they differ in their anatomical substrate from irregular ones: both are stored in a network of whole forms that activates the ventral pathway bilaterally, specifically, BA47, the temporal pole, and anterior MTG [32]. (The transparent derived forms, however, showed different patterns of activity within this network from the opaque ones.) We speculate that the nondecompositional (Basic) nature of derivation may explain why G-SLI children are competent at generating derived forms (albeit not always with the proper choice of suffix).

\section{Phonology}

A recent model of the cortical organization of phonology [35] makes a distinction similar to what we call Basic and Extended phonological processing (Figure 4). The auditory input is first subjected to spectrotemporal analyses in auditory cortex bilaterally (though with some hemispheric differences), and then phonological analysis in the Superior Temporal Sulcus, before it splits into two streams. One is a left-hemisphere dorsal pathway which relates words' sounds to their articulation; it is deployed in word learning, speech monitoring, verbal working memory, and the articulation of long, complex, low-frequency, and novel words. The other is a bilateral ventral pathway which relates words' sounds to their meanings, and from there to diffuse bilateral conceptual networks, as well as to a left-hemisphere anterior temporal "combinatorial network."

The dorsal network appears to overlap the dorsal network proposed for syntax and morphology; the ventral pathway, the two ventral networks proposed by Friederici for syntax. The dorsal pathway seems to underlie the Extended Phonological skills that challenge SLI children, such as repeating or generating words with complex sequences of clusters, 
syllables, or suffixes, and disambiguating phrases based on their prosody. The less-affected Basic Phonological processes, such as perceiving, discriminating, and exchanging phonemes, appear to be handled by areas for auditory and phonological analysis prior to the dorsal-ventral split, possibly a dorsal sub-stream extending to premotor areas (see Figure 4), and the ventral pathway, since G-SLI children are relatively good at recognizing words from their sounds.

\section{The brains of Individuals with SLI}

\section{Neuroanatomy}

A recent meta-analysis of 25 studies of the neuroanatomical correlates of broad SLI revealed consistent structural anomalies in two regions: frontal cortex, particularly Broca's Area and its right-hemisphere homologue, and the caudate nucleus [60]. The findings are generally consistent with SLI being a deficit of Extended processing (though Broca's participates in aspects of Basic syntax and probably Basic morphology as well). The heterogeneity of SLI may mean that any meta-analysis of the entire syndrome will average away more specific neuroanatomical differences associated with its subtypes, including GSLI.

\section{Electrophysiology and Functional Neuroimaging}

Studies of ev,ent-related potentials have found that G-SLI speakers, unlike unimpaired controls, fail to show a difference in their Early Syntactic Brain Response between sentences with violations of movement and traces (Who did Barbie push the clown into the wall?) and their grammatical counterparts, presumably because they cannot parse the correct versions and so treat them as ungrammatical. The G-SLI participants also show an unexpected parietal right-lateralised N400-like response, co-occurring with a typical P600 [20,61]. The presence of the N400-like response (ordinarily elicited by semantically anomalous 
sentences) suggests that individuals with G-SLI may be using ventral networks for lexical and semantic syntactic processing, perhaps to compensate for their deficit with Extended syntax [20]. French-, German-, and Italian-speaking individuals with SLI [62-65] showed a similar pattern. Looking within a similar time window (250-400 ms) at responses of Englishspeaking children with broad SLI to grammatical words, other investigators found reduced or reversed asymmetries from sources in the lateral surfaces of the temporal cortices, and the absence of a deep neural generator in the hippocampus or basal ganglia \{Shafer, 2001 \#2572;Shafer, 2000 \#2573; Neville, 1993 \#1171\}.

The functional and neuroanatomical data on SLI are still too coarse (both in SLI subcategories and neuroanatomical pathways) to strongly support the theory that G-SLI is caused by defects in the anatomical systems underlying Extended grammatical processing, but they are broadly consistent with it. They point to the left IFG, particularly BA44 and BA45, BA22 (superior temporal lobe), fibre tracts of the dorsal route which connect them, and to the basal ganglia.

\section{Genetic Correlates of Grammar Impairments}

Language impairment is highly heritable $[66,67]$, but as with all heritable variation, the individual genes underlying the variation have been elusive [68]. In this regard, SLI has seen more success than other psychological traits: to date, four candidate genes have been robustly associated with it

The FOXP2 gene on chromosome 7q, which codes for a transcription factor that regulates many other genes, is perfectly associated within a large extended family (and in a small number of unrelated individuals) with a form of SLI which co-occurs with verbal dyspraxia (a motor-speech disorder). The sequence of the FOXP2 gene in humans differs from that in nonhuman primates, and has been identified as a target of natural selection [69 2305]. 
The CNTNAP2 gene on chromosome 7q (downstream from FOXP2) is associated with genetically complex forms of SLI, where different genetic variants are risk factors for the disorder [70]. The gene is also associated with Autism, Dyslexia and other developmental disorders that impact on language [70]. Its main linguistic manifestation demonstrated so far is in non-word repetition, which requires phonological analysis and memory, though it also associated with low composite scores for expressive and receptive language $[8,70]$. Unimpaired Individuals with the CNTNAP2 alleles associated with SLI and autism have increased contralateral fMRI activation in the right frontal operculum (BA44) and middle temporal gyrus (BA 21), suggesting that CNTNAP2 variants can affect brain areas associated with language even in the general population [71].

Two additional genes that appear specific to SLI are on chromosome 16q: ATP2C2 and CMIP. Both appear to cause an impairment of phonology and phonological memory [72]. Other studies have implicated other genes, with varying degrees of replicability and specificity [73]. All the genes associated with SLI appear to affect early embryonic development $[7,8]$. During cortical neurogenesis they are expressed in similar brain regions, including deep layers of the cerebral cortex, striatum and cerebellum, presumably leading to abnormal neurobiological pathways later in life.

A limitation of the extant literature is that most studies have used non-specific tests of language that do not isolate aspects of processing or their neural correlates. We suggest that a more promising strategy for discovering links to genes is to identify intermediate phenotypes consisting of functional and anatomical brain circuits which underlie particular aspects of the impairment (such as the distinction between Basic and Extended processing which we suggest characterizes the G-SLI subtype). The use of quick yet reliable tests (such as the Grammar And Phonology Screening test [74, 75], which can identify G-SLI by testing 
extended syntax, morphology and phonology, promises to add new precision to the study of the genetic correlates of language impairment.

\section{Conclusion}

We have suggested that the study of language impairment has opened a new frontier of research which promises a comprehensive biological understanding of language, from evolution and genes through neuroanatomy and neural function to linguistic computation and then to overt speech and comprehension. These advances depend on a multi-level approach. Rather than mapping genetic variants directly to overall language impairment, researchers must characterize the intermediate links by probing for finer-grained linguistic components and modes of processing together with their neural substrates.

As a preliminary example, we have argued for a distinction between a family of Basic representations and processes and a family of Extended ones. Extended syntax involves hierarchical, composed phrase structures, abstract rules, and movement; Basic syntax involves local phrases, lexical retrieval, and interpretation based on lexical semantics. Extended morphology involves multimorphemic, composed, regular forms; Basic morphology involves the retrieval of whole words comprising irregular, derived, or highfrequency regular forms. Extended phonology involves the composition of complex syllables and higher prosodic units out of segments; Basic phonology involves discriminating and isolating segments and retrieving stored lexical forms. In all three components the Extended representations and processes are substantially more impaired than the Basic ones. Furthermore, the behavioural impairment with Extended grammar may be caused by abnormalities in the anatomy or functioning of distinct neural pathways, particularly dorsal circuits in which the arcuate fasciculus links regions in the superior posterior temporal lobe to the left inferior frontal gyrus, with further interconnections with the left basal ganglia. The pattern of impairment in G-SLI thus points to a set of neural pathways underlying Extended 
processing which appear to be a recently evolved, late developing, and genetically complex substrate for the most distinctively human cognitive trait. 


\section{Figure 1 Caption}

\section{Examples of Extended Syntax}

The English rules for forming questions and marking tense and agreement are complex and belong to what we call Extended Syntax. Questions with wh-words (who, what, which, etc.) such as those in (B-F) require movement (solid arrows) from an underlying position (underscore) to a position in the surface string. The result of the movement is audible when the wh-word corresponds to an object $(C)$, the subject of an embedded clause (D, E), or the object of a preposition (F), but it is covert when the wh-word corresponds to the subject of a main clause (B). Tense and subject-verb agreement are obligatory in English main clauses; in wh-questions they must be marked on the auxiliary do if the clause lacks any another auxiliary, and the auxiliary must be inverted with the subject (Did he leave? rather than Left he?). These operations are handled by a complex sequence of movement and featurechecking operations which we abbreviate here with dashed lines. If checking or movement has not been reliably computed, as (we hypothesize) is common in G-SLI, then for verbs that should be marked for tense, the infinitival form may be used instead, and the auxiliary may be omitted. For wh-questions, the problem may be manifested as a filled gap or, if the movement is partial, the wh-word may be copied in the medial moved position (D, E). See Table 1 for examples of errors produced by such children.

\section{Figure 2}

\section{Neural Correlates of Extended and Basic Syntax}

Syntactic processing in the brain is implemented in distinct dorsal and ventral circuits which may correspond to Extended and Basic syntax (Friederici, 2009 \#2694;Friederici, 2012 
\#8487\}. The dorsal route (solid red arrow) links Brodmann Area 44 (BA44, a part of Broca's Area) via the arcuate fasciculus to the posterior Superior Temporal Gyrus (STG, a part of Wernicke's Area); this pathway has been implicated in complex syntactic processing, including hierarchical phrase structure and movement, that is, Extended syntax. The caudate nucleus of the basal ganglia (not shown), a subcortical structure, is interconnected with frontal cortex, and it has also been found to affect Extended syntax. The first of the two ventral circuits (blue arrow) links the frontal operculum (FO, the cortex inferior and medial to BA 44 and 45, mostly hidden) via the uncinate fasciculus to the anterior STG; it supports local phrase structure. The second (purple arrow) links Brodmann Areas 45 (BA45, another part of Broca's Area) and 47 via the Extreme Capsule Fibre System to the middle portion of the superior and middle temporal lobe; it supports retrieval of stored words and associated semantic processing. The two ventral pathways thus may correspond to Basic syntactic processing.

\section{Figure 3}

\section{Neural Correlates of Extended and Basic Morphology}

Regular inflectional forms (walked, played) are computed by Extended processes that closely overlap with those underlying Extended syntax, namely BA 45 extending into BA 44 and BA47, the arcuate fasciculus, and the superior and middle temporal cortex (MarslenWilson, $2007 \# 6530$.$\} The frontal regions are part of a circuit that also includes the caudate$ nucleus (not shown). In contrast, the storage and retrieval of irregular forms (brought, went) appears to be mediated bilaterally (blue outline) in a more diffuse set of posterior and middle temporal lobe structures (Tyler, 2005 \#9670\}. Derived morphological forms, both regular (bravely) and irregular (archer), activate a third, bilateral network, which we tentatively associate with the ventral pathway, specifically, BA47 extending into BA45, and the anterior Superior and Middle Temporal gyri (purple lines) [32]. This network may support a network 
of related but whole word forms. Individuals with G-SLI are impaired in productive regular inflection, an Extended process that engages the dorsal route, but their performance is less impaired with the retrieval of irregular and derived forms, a Basic process which is more tried to lexical memory, and which engages bilateral ventral and posterior routes.

\section{Figure 4:}

\section{Neural Correlates of Extended and Basic Phonology}

Phonological processing begins with spectrotemporal and segmental processing in bilateral auditory cortex (Superior Temporal Gyrus, STG, and Superior Temporal Sulcus, STS; right hemisphere not shown). From there it splits into two streams. A left-hemisphere Dorsal stream runs to a sensorimotor integration area in the Sylvian portion of the parietal-temporal junction (SPT), and from there further bifurcates into a pathway along the Superior Longitudinal Fasciculus to premotor areas (PM; pink arrow) and a pathway along the Arcuate Fasciculus to Broca's Area (BA44; red arrow). These pathways connect acoustic speech representations to articulatory ones, the former perhaps to basic articulatory phonetic skills, the latter to complex syllables and words, self-monitoring speech, and verbal working memory. A bilateral Ventral stream (right hemisphere portion not shown) runs from auditory cortex to the Middle and Inferior Temporal Gyri (MTG and ITG), and from there to the anterior Temporal lobe, and also to a conceptual network widely distributed through the temporal and other lobes. This pathway connects the sounds of words to their meanings. We suggest that the Extended Phonology which challenges G-SLI is associated with the part of the Dorsal pathway that runs to Broca's Area (red), but perhaps not the part that runs to Premotor areas (pink), as articulation in the syndrome is relatively unimpaired. Basic Phonology is associated with acoustic and phonological analysis in auditory cortex and with the Ventral pathway. 


\section{Table 1 caption.}

\section{Patterns of Errors with wh-questions by Language-Impaired}

\section{Children}

Table 1 summarizes experiments with G-SLI children investigating wh- questions (who, what, which) in production, grammaticality judgments, on-line cross-modal priming, and EEG recordings. In each experiment the children failed to compute the Extended syntactic relations between the wh-word and the position to which it is related (Figure 1). The diversity of methods and tasks suggest that the deficit is independent of the paradigm and processing demands. Similar patterns are found with French, Italian, German, Hebrew and Greek [14$16,76,77]$

The Elicitation task [78] shows that children and teenagers with G-SLI fail to compute fillergap relations and fail to check and mark tense (Figure 1). In the Sentence Judgment task [79], G-SLI teenagers correctly reject semantic violations and accept grammatical sentences, but incorrectly accept sentences with errors in filler-gap relations and tense. The task Eliciting Embedded Questions [80] illustrates omission of the auxiliary did and a copying error, where the wh-word is only partially moved and ends up in an intermediate position. The Cross-Modal Priming study [24] shows that in children and teenagers with GSLI, a wh-filler does not prime its related word at the gap position, though it does prime it at the verb's offset, suggesting they are sensitive to the verb 's semantics. The ERP study [20] shows that G-SLI teenagers have an appropriate response (the N400) to violations of lexical semantics (i and ii). Responses of violations to syntax were tested with wh-questions in which agents perform actions on inanimate objects. Unimpaired subjects perceive a syntactic violation as soon as they encounter an animate noun that could be linked with the wh-word, such as clown in (iv), and thus show an Early Syntactic Brain Response (ESBR); the G-SLI subjects instead show the N400 ordinarily elicted by semantic violations. 
Table 1

\begin{tabular}{|c|c|c|c|c|}
\hline Task & Description & $\begin{array}{l}\text { Lead-in or prime } \\
\text { (see Fig } 1 \text { for the } \\
\text { syntactic structure) }\end{array}$ & $\begin{array}{l}\text { Control child's } \\
\text { typical } \\
\text { response }\end{array}$ & $\begin{array}{l}\text { Child with G-SLl's } \\
\text { response }\end{array}$ \\
\hline $\begin{array}{l}\text { Elicitation } \\
\text { of wh- } \\
\text { questions }\end{array}$ & $\begin{array}{l}\text { wh-subject question } \\
\text { wh-object question }\end{array}$ & $\begin{array}{l}\text { Someone saw Mrs } \\
\text { White. Ask me who. } \\
\text { Mrs White stole a ring. } \\
\text { Ask me which one? }\end{array}$ & $\begin{array}{l}\text { Who saw Mrs } \\
\text { White? } \\
\text { Which ring did } \\
\text { Mrs White steal? }\end{array}$ & $\begin{array}{l}\text { Who someone see } \\
\text { Mrs White? } \\
\text { Which [....] Mrs } \\
\text { White stole the } \\
\text { ring? }\end{array}$ \\
\hline $\begin{array}{l}\text { Sentence } \\
\text { Judgements }\end{array}$ & $\begin{array}{l}\text { Semantic } \\
\text { judgement } \\
\text { Syntactic } \\
\text { judgement: Tense } \\
\text { Syntactic } \\
\text { judgement: wh- } \\
\text { movement }\end{array}$ & $\begin{array}{l}\text { i) Barbie bakes the } \\
\text { cakes } \\
\text { ii) Barbie drinks the } \\
\text { cakes } \\
\text { i) Who did Mrs White } \\
\text { see? } \\
\text { ii) Who did Mrs White } \\
\text { saw? } \\
\text { i) Who did Mrs White } \\
\text { see? }\end{array}$ & $\begin{array}{l}\text { i). Yes } \\
\text { ii). No } \\
\text { i). Yes } \\
\text { ii). No } \\
\text { i). Yes } \\
\text { ii). No }\end{array}$ & $\begin{array}{l}\text { i). Yes } \\
\text { ii). No } \\
\text { i). Yes } \\
\text { ii). Yes } \\
\text { i). Yes } \\
\text { ii). Yes }\end{array}$ \\
\hline $\begin{array}{l}\text { Elicitation } \\
\text { of } \\
\text { Embedded }\end{array}$ & $\begin{array}{l}\text { Embedded subject } \\
\text { wh-question }\end{array}$ & $\begin{array}{l}\text { Joe thought someone } \\
\text { hit the man. Ask me } \\
\text { who? }\end{array}$ & $\begin{array}{l}\text { Who did Joe } \\
\text { think hit the } \\
\text { man? }\end{array}$ & $\begin{array}{l}\text { Who did Joe think } \\
\text { who hit the man? }\end{array}$ \\
\hline
\end{tabular}




\begin{tabular}{|c|c|c|c|c|}
\hline $\begin{array}{l}\text { wh- } \\
\text { questions }\end{array}$ & $\begin{array}{l}\text { Embedded object } \\
\text { wh-question }\end{array}$ & $\begin{array}{l}\text { Joe thought Mr White } \\
\text { hit someone. Ask me } \\
\text { who? }\end{array}$ & $\begin{array}{l}\text { Who did Joe } \\
\text { think Mr White } \\
\text { hit? }\end{array}$ & $\begin{array}{l}\text { Who }[\ldots . .] \text { Joe think } \\
\text { Mr White hit } \\
\text { someone? }\end{array}$ \\
\hline $\begin{array}{l}\text { Cross- } \\
\text { modal } \\
\text { Sentence- } \\
\text { Picture } \\
\text { Priming }\end{array}$ & $\begin{array}{l}\text { The child is shown } \\
\text { a picture of a rabbit } \\
\text { or a ladder at one } \\
\text { of three points } \\
\text { during a spoken } \\
\text { sentence and } \\
\text { presses a button } \\
\text { indicating whether it } \\
\text { is animate or } \\
\text { inanimate. } \\
\text { Response time for } \\
\text { position [2], after } \\
\text { the adjective, } \\
\text { serves as a control. } \\
\text { Priming (faster } \\
\text { responding) at } \\
\text { position [1] shows } \\
\text { sensitivity to basic } \\
\text { verb semantics } \\
\text { (give + recipient). } \\
\text { Priming at position } \\
\text { [3] (the wh-gap) } \\
\text { shows sensitivity to } \\
\text { syntactic } \\
\text { movement: the } \\
\text { rabbit matches the }\end{array}$ & 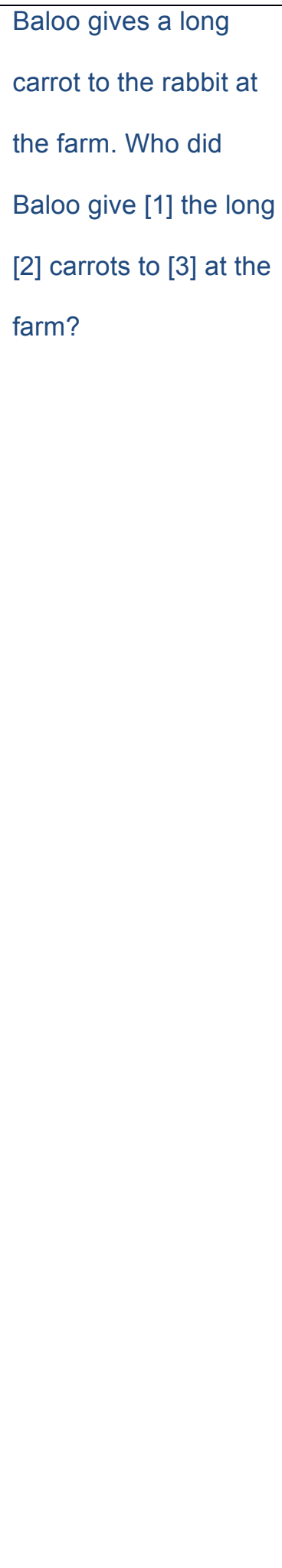 & $\begin{array}{l}\text { [1] No priming. } \\
\text { [2] No priming. } \\
\text { [3] Priming. }\end{array}$ & $\begin{array}{l}\text { [1] Priming. } \\
\text { [2] No priming. } \\
\text { [3] No priming. }\end{array}$ \\
\hline
\end{tabular}




\begin{tabular}{|c|c|c|c|c|}
\hline & $\begin{array}{l}\text { who which had } \\
\text { been moved from } \\
\text { that position. }\end{array}$ & & & \\
\hline \multirow[t]{2}{*}{$\begin{array}{l}\text { Event } \\
\text { Related } \\
\text { Potentials } \\
\text { (ERP) }\end{array}$} & $\begin{array}{l}\text { Violation of } \\
\text { expectation based } \\
\text { on semantics (ERP } \\
\text { time-locked to the } \\
\text { underlined word) }\end{array}$ & $\begin{array}{l}\text { i). Control: Barbie } \\
\text { bakes the cakes in } \\
\text { the oven. } \\
\text { ii).Violation: Barbie } \\
\text { bakes the people in } \\
\text { the oven. }\end{array}$ & N400 & N400 \\
\hline & $\begin{array}{l}\text { Violation of } \\
\text { expectation based } \\
\text { on syntax (ERP } \\
\text { time-locked to the } \\
\text { underlined word) }\end{array}$ & $\begin{array}{l}\text { iii). Control: Who did } \\
\text { Barbie push the ball } \\
\text { into? } \\
\text { iv). Violation: Who did } \\
\text { Barbie push the clown } \\
\text { into the wall? }\end{array}$ & ELAN, P600 & 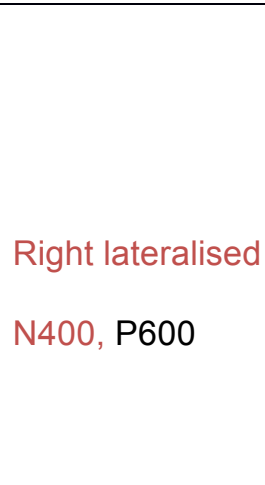 \\
\hline
\end{tabular}




\section{Box 1}

\section{Components of Language}

Language is traditionally divided into several subsystems [81]:

- Syntax: The combination of words into phrases and sentences, and assignment of grammatical relations (subject, object, head, etc.) which determine their compositional meaning.

- Morphology: The combination of words or parts of words (morphemes) into new words, further subdivided into inflection (modifying a word according to its role in the sentence) and derivation (creating a new word from old ones).

- Phonology: The combination of sounds into morphemes, and the modification of sounds according to their contexts.

- Pragmatics: Principles governing the use of language in a discourse and communicative context.

- Lexicon: The component of memory which stores words, idioms, and other fixed forms.

We concentrate on the first three, and propose that they are cross-classified by a distinction in representation and processing:

Extended grammatical representations are

- abstract, consisting of categories defined by their grammatical privileges rather than their semantic content

- hierarchical, defined by a tree of constituents embedded in larger constituents

- nonlocal, potentially spanning long distances in the string

- composed, namely assembled into meaningful combinations by rules

- Basic grammatical representations are

- semantic and lexical, consisting of words or features of meaning

- linear, defined by left-to-right ordering

- local, involving adjacent or nearby elements

- holistic, consisting of entire assemblies stored in memory

\section{Box 2}




\section{Outstanding questions}

- Can subtypes of SLI (such as the Grammatical-SLI discussed in this paper) be reliably identified across populations, languages, and laboratories?

- Can more sensitive methods of neural function, cortical and subcortical anatomy, and tractography identify the neural substrates of different language components more precisely?

"Geno's paradox" is the failure to pinpoint specific genes that underlie massively heritable traits, presumably because most behavioural traits involve either many genes with small effects, rare genes with larger effects, or both. Will new genomic methods designed to resolve the paradox identify additional genetic contributors to SLI?

-What are the patterns of overlap and non-overlap in language disabilities, neruoanatomical differences, and genetic causes between different forms of SLI, other developmental disorders (e.g., Autistic Spectrum Disorders), and degenerative disorders (such as Huntington's and Parkinson's Disease?

- Are there forms of language impairment that show impaired Basic representations and ventral pathways, but relatively spared dorsal pathways?

- What are the clinical implications with respect to focused remediation in children with SLI? Should we attempt to strengthen their Extended processes, or encourage them to compensate using their strengths in Basic representations? 


\section{Authors' Note}

This paper is a capstone to the research of Heather van der Lely, who died of cancer in February, 2014. She identified the grammatical subtype of SLI, characterized it empirically (with collaborators in London, Paris, Louvain la Neuve, and Berlin), proposed the ExtendedBasic distinction to explain the pattern of deficits, and wrote the first draft of this paper. Steven Pinker rewrote and fact-checked the paper before and after Heather's death, with extensive input from her main collaborator Chloe Marshall and from John Harris, Gary Marcus, William Marslen-Wilson, David Poeppel, Friedemann Pulvermüller, Uli Sauerland, Michael Ullman, and two anonymous reviewers. This research was supported by the Wellcome Trust (grant 063713), the Economic and Social Research Council, the Medical Research Council, The EU $7^{\text {th }}$ Programme (Grant CLAD 135295 LLP-1-2007-UK Kat SRC), the Leverhulme Trust, and the PD Fund at ZAS Berlin. Special thanks go to Heather's husband Paul Richens for drafting the figures, retrieving records, and much else. 


\section{References}

1 Broca, P. (1861) Remarques sur le siege de la faculte du languge articule suivies d'une observation d/aphemie (parte de la parole). Bull Soc Anal Paris 6, 330-357

2 Wernicke, C. (1874) Der aphasischa symotomen complex. Springer Verlag

3 Geschwind, N. (1979) Specializations of the human brain. In Sci Am

4 van der Lely, H.K. (2005) Domain-specific cognitive systems: insight from GrammaticalSLI. Trends Cogn Sci 9, 53-59

5 Walenski, M., et al. (2006) Language in Autism. In Understanding Autism: From Basic Neuroscience to Treatment (Moldin, S.O. and Rubenstein, J.L., eds), pp. 175-203, Boca Raton, FL: Taylor and Francis Books.

6 Cohen, N.J., et al. (2000) The interface between ADHD and language impairment: an examination of language, achievement, and cognitive processing. J Child Psychol Psychiatry 41, 353-362

7 Fisher, S.E., et al. (2003) Deciphering the genetic basis of speech and language disorders. Annu Rev Neurosci 8, 8

8 Newbury, D.F., et al. (2010) Recent advances in the genetics of language impairment. Genome Med 2, 6

9 van der Lely, H.K. and Marshall, C.R. (2010) Assessing component language deficits in the early detection of reading difficulty risk. $J$ Learn Disabil 43, 357-368

10 van der Lely, H.K. and Marshall, C. (2011) Grammatical-specific language impairment: A window onto domain specificity. In The handbook of psycholinguistics and cognitive processes: Perspectives in communication disorders (Gouendouzi, J., et al., eds), pp. 401418, Psychology Press

11 van der Lely, H.K. and Stollwerck, L. (1996) A grammatical specific language impairment in children: an autosomal dominant inheritance? Brain Lang 52, 484-504

12 Norbury, C., et al. (2002) Does impaired grammatical comprehension provide evidence for an innate grammar module? Applied Psycholinguistics 23, 247-268

13 Leonard, L.B. (2007) Processing limitations and the grammatical profile of children with specific language impairment. Adv Child Dev Behav 35, 139-171

14 Hamann, C., et al. (1998) German impaired grammar: The clause structure revisited. Language Acquisition 7, 193-245

15 Stavrakaki, S. and van der Lely, H. (2010) Production and comprehension of pronouns by Greek children with specific language impairment. Brit J Dev Psychol 28, 189-216

16 Friedmann, N. and Novogrodsky, R. (2007) Is the movement deficit in syntactic SLI related to traces or to thematic role transfer? Brain and Language 101, 50-63

17 Marcus, G.F. (2001) The Algebraic Mind. MIT Press

18 Pinker, S. (1999) Words and Rules: The ingredients of language. Weidenfeld \& Nicolson

19 Chomsky, N. (1995) The minimalist program. MIT press

20 Fonteneau, E. and van der Lely, H.K. (2008) Electrical brain responses in languageimpaired children reveal grammar-specific deficits. PLoS One 3, e1832

21 Adani, F., et al. (2013) Number dissimilarities facilitate the comprehension of relative clauses in children with (Grammatical) Specific Language Impairment. J Child Lang, 1-31

22 van der Lely, H.K. (1996) Specifically language impaired and normally developing children: Verbal passive vs adjectival passive sentence interpretation. Lingua 98, 243-272 
23 van der Lely, H.K., et al. (1998) Evidence for a grammar-specific deficit in children. Curr Biol 8, 1253-1258

24 Marinis, T. and van der Lely, H.K. (2007) On-line processing of wh-questions in children with G-SLI and typically developing children. Int $J$ Lang Commun Disord 42, 557-582

25 Rice, M., et al. (1998) Tense over time: the longitudinal course of tense acquisition in children with Specific Language Impairment. Journal of Speech, Language and Hearing Research 41, 1412 -1431

26 Pinker, S. and Ullman, M.T. (2002) The past and future of the past tense. Trends in Cognitive Sciences 6, 456-463

27 Rice, M., et al. (2004) Grammatical tense deficits in children with SLI and nonspecific language impairment: Relationships with nonverbal IQ over time. Journal of Speech, Language and Hearing Reseach 47, 816-834

28 Ullman, M. and Gopnik, M. (1999) The production of inflectional morphology in hereditary specific language impairment. Applied Psycholinguistics 20, 51-117

29 van der Lely, H.K. and Ullman, M.T. (2001) Past tense morphology in specifically language impaired children and normally developing children. Language and Cognitive Processes 16, 113-336

30 Marshall, C.R. and van der Lely, H. (2012) Irregular past tense forms in English: How children with specific language impairment contribute to models of morphology. Morphology 22, 122- 142

31 Marshall, C.R. and van der Lely, H.K. (2006) A challenge to current models of past tense inflection: The impact of phonotactics. Cognition 100, 302-320

32 Bozic, M., et al. (2013) Neurobiological systems for lexical representation and analysis in English. J Cognitive Neurosci 25, 1678-1691

33 Marshall, C.R. and Van der Lely, H.K.J. (2007) Derivational morphology in children with grammatical-specific language impairment. Clin Linguist Phonet 21, 71-91

34 Selkirk, E.O. (1984) Phonology and syntax: The relation between sound and structure. MIT Press

35 Hickok, G. and Poeppel, D. (2007) The cortical organization of speech processing. Nat Rev Neurosci 8, 393-402

36 Poeppel, D., et al. (2008) Speech perception at the interface of neurobiology and linguistics. Philos Trans R Soc Lond B Biol Sci 363, 1071-1086

37 Ramus, F., et al. (2013) Phonological deficits in specific language impairment and developmental dyslexia: towards a multidimensional model. Brain 136, 630-645

38 Marshall, C.R., et al. (2011) Do children with dyslexia and/or specific language impairment compensate for place assimilation? Insight into phonological grammar and representations. Cogn Neuropsychol 27, 563-586

39 Marshall, C.R. and van der Lely, H.K. (2009) Effects of word position and stress on onset cluster production: Evidence from typical development, SLI and dyslexia. Language 85, 3957

40 Marshall, C.R. and van der Lely, H.K. (2007) The impact of phonological complexity on past tense inflection in children with Grammatical-SLI. Advances in Speech Language Pathology 9, 191-203

41 Gallon, N., et al. (2007) Non-word repetition: An investigation of phonological complexity in children with Grammatical SLI. Clin Linguist Phonet 21, 435-455

42 Marshall, C.R., et al. (2009) The link between prosody and language skills in children with specific language impairment (SLI) and/or dyslexia. Int $J$ Lang Commun Disord 44, 466-488 43 Friederici, A.D. (2009) Pathways to language: fiber tracts in the human brain. Trends Cogn Sci 13, 175-181

44 Friederici, A.D. (2012) The cortical language circuit: from auditory perception to sentence comprehension. Trends Cogn Sci 16, 262-268

45 Marslen-Wilson, W.D. and Tyler, L.K. (2007) Morphology, language and the brain: the decompositional substrate for language comprehension. Philos Trans R Soc Lond B Biol Sci $362,823-836$ 
46 Shtyrov, Y., et al. (2003) Grammar processing outside the focus of attention: an MEG study. J Cogn Neurosci 15, 1195-1206

47 Herrmann, B., et al. (2009) Localization of the syntactic mismatch negativity in the temporal cortex: an MEG study. Neuroimage 48, 590-600

48 Hanna, J., et al. (2013) Early activation of Broca's area in grammar processing as revealed by the syntactic mismatch negativity and distributed source analysis. $J$ Cognitive Neurosci

49 Friederici, A.D. (2012) Language development and the ontogeny of the dorsal pathway. Front Evol Neurosci 4, 3

50 Oberecker, R. and Friederici, A.D. (2006) Syntactic event-related potential components in 24-month-olds' sentence comprehension. Neuroreport 17, 1017-1021

51 Friederici, A.D. (2002) Towards a neural basis of auditory sentence processing. Trends Cogn Sci 6, 78-84

52 Mestres-Misse, A., et al. (2012) An anterior-posterior gradient of cognitive control within the dorsomedial striatum. Neuroimage 62, 41-47

53 Ullman, M.T., et al. (1997) A neural dissociation within language: Evidence that the mental dictionary is part of declarative memory, and that grammatical rules are processed by the procedural system. $J$ Cognitive Neurosci 9, 266-276

54 Ullman, M.T. (2004) Contributions of memory circuits to language: the declarative/procedural model. Cognition 92, 231-270

55 Sahin, N.T., et al. (2006) Abstract grammatical processing of nouns and verbs in Broca's area: Evidence from fMRI. Cortex 42, 540-562

56 Sahin, N.T., et al. (2009) Sequential Processing of Lexical, Grammatical, and Phonological Information Within Broca's Area. Science 326, 445-449

57 Ullman, M.T., et al. (2014) The functional neuroanatomy of regular and irregular morphology. in preparation

58 Tyler, L.K., et al. (2005) Differentiating lexical form, meaning, and structure in the neural language system. P Natl Acad Sci USA 102, 8375-8380

59 Tyler, L.K. (2005) Temporal and frontal systems in speech comprehension: An fMRI study of past tense processing. Neuropsychologia 43, 1963-1974

60 Ullman, M.T., et al. (2014) Brain abnormalities in Specific language Impairment are localized to frontal regions and the caudate nucleus. under revision

61 Hestvik, A., et al. (2007) ERP measure of gap-filling in children with and without specific language impairment. In CUNY Sentence processing conference

62 Sabisch, B., et al. (2006) Lexical-semantic processes in children with specific language impairment. Neuroreport 17, 1511-1514

63 Sabisch, B., et al. (2009) Children with specific language impairment: the role of prosodic processes in explaining difficulties in processing syntactic information. Brain Res 1261, 3744

64 Cantiani, C., et al. (2010) ERP correlates of anomalous morphosyntactic processing in adutls and childrne with developmental dyslexia. In Boston University Conference on Language Development, Cascadilla Press

65 Pizzioli, F., et al. (2007) Abnormal interaction between semantic and syntactic processing in specific language impairment: Electrophysiological evidence. In Proceeding of the British Psychological Society

pp. 203-240, British Psychological Society

66 Stromswold, K. (2001) The heritability of language: A review and meta-analysis of twin and adoption studies. Language 77, 647-723

67 Ganger, J. and Stromswold, K. (1998) Innateness, evolution, and genetics of language. Hum Biol 70, 199-213

68 Chabris, C.F., et al. (2013) Why is it hard to find genes that are associated with social science traits? . American Journal of Public Health 103, 152-166

69 Enard, W., et al. (2002) Molecular evolution of FOXP2, a gene involved in speech and language. Nature 418, 869-872 
70 Newbury, D.F., et al. (2009) CMIP and ATP2C2 modulate phonological short-term memory in language impairment. Am J Hum Genet 85, 264-272

71 Whalley, H.C., et al. (2011) Genetic variation in CNTNAP2 alters brain function during linguistic processing in healthy individuals. Am J Med Genet B Neuropsychiatr Genet 156, 941-948.

72 Newman, A.J., et al. (2011) The Influence of Language Proficiency on Lexical Semantic Processing in Native and Late Learners of English. J Cogn Neurosci

73 Rice, M.L., et al. (2009) Convergent genetic linkage and associations to language, speech and reading measures in families of probands with Specific Language Impairment. $J$ Neurodev Disord 1, 264-282

74 Gardner, H., et al. (2006) Development of the Grammar and Phonology Screening (GAPS) test to assess key markers of specific language and literacy difficulties in young children. Int J Lang Commun Disord 41, 513-540

75 van der Lely, H.K., et al. (2011) An investigation to validate the grammar and phonology screening (GAPS) test to identify children with specific language impairment. PLoS One 6, e22432

76 Stavrakaki, S. (2001) Comprehension of reversible relative clauses in specifically language impaired and normally developing Greek children. Brain and Language 77, 419431

77 Jakubowicz, C. and Tuller, L., eds (2008) Specific language impairment in French. john Benjamins

78 van der Lely, H.K. and Battell, J. (2003) Wh-movement in children with grammatical SLI: A test of the RDDR hypothesis. Language 79, 153-181

79 van der Lely, H.K., et al. (2011) Who did Buzz see someone? Grammaticality judgement of wh-questions in typically developing children and children with Grammatical-SLI. Lingua $121,408-422$

80 Archonti, A. (2003) Wh-Question Formation in Typically Developing Children and Children with Grammatical SLI. In Centre for Developmental Language Disorders and Cognitive Neuroscience, Dept of Human Communication Sciences., University College London

81 Jackendoff, R. (1997) The Architecture of the Language Faculty. MIT Press 